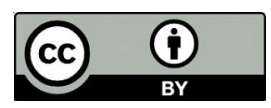

UDC 81’25:35.077.535.6

LBC 81.18
Submitted: 14.12 .2020

Accepted: 30.03 .2021

\title{
EASY AND PLAIN LANGUAGE TRANSLATION AS AN INTRALINGUAL TYPE OF TRANSLATION \& TRAINING THE INTRALINGUAL TRANSLATORS
}

\author{
Natalya V. Nechaeva \\ Herzen State Pedagogical University of Russia, Saint Petersburg, Russia \\ Krishna-Sara Helmle \\ Translation Company and Consultancy \\ for Easy-to-Read and Plain Language “Textöffner®”, Tübingen, Germany
}

\section{Emma M. Kairova}

Founder and CEO at LSP and Mentorship project for translators "PROtranslation”, Nalchik, Russia

\begin{abstract}
The article explores the principles of intralingual translation of texts into easy and plain languages, specifies the necessary competencies of specialists in this field and identifies the main characteristics, peculiarities and areas of intralingual translation application. The differentiation of key concepts of "translation into easy language" and "translation into plain language" is presented. The competencies needed for these types of text translations are outlined and exemplified by the analysis of text translation into easy Russian. The researchers point out the necessity to single out linguistic and extralinguistic factors at the pre-translation stage of original text analysis, and take into consideration the communicative background of translation. The assessment of the practical experience of training translators in easy and plain language in Germany made it possible to draw conclusions about the possibilities and content of training in this field in Russia. The results of the research can be applied while developing university training programs for translators, as well as in public and commercial organizations when creating an accessible environment in easy and plain language for effective communication with their target audience. In addition, the article may be of interest to practicing interlingual translators who would like to enhance their skills in this area.
\end{abstract}

Key words: intralingual translation, easy language, plain language, digital accessibility, easy language translation, plain language translation, translator training.

Citation. Nechaeva N.V., Helmle K.-S., Kairova E.M. Easy and Plain Language Translation as an Intralingual Type of Translation \& Training the Intralingual Translators. Vestnik Volgogradskogo gosudarstvennogo universiteta. Seriya 2. Yazykoznanie [Science Journal of Volgograd State University. Linguistics], 2021, vol. 20 , no. 3, pp. 99-108. (in Russian). DOI: https://doi.org/10.15688/jvolsu2.2021.3.9

\section{ПЕРЕВОД НА ЯСНЫЙ И / ИЛИ ПРОСТОЙ ЯЗЫКИ КАК ИНТРАЛИНГВАЛЬНЫЙ ВИД ПЕРЕВОДА И ПОДГОТОВКА ПЕРЕВОДЧИКОВ}

\author{
Наталья Викторовна Нечаева
}

Российский государственный педагогический университет им. А.И. Герцена, г. Санкт-Петербург, Россия 
Кришна-Сара Хельмле

Переводческая и консалтинговая компания Textöffner ${ }^{\circledR}$, г. Тюбинген, Германия

Эмма Магомедовна Каирова

Переводческая компания и наставнический проект для переводчиков ООО «Протранслейшн», г. Нальчик, Россия

Аннотация. В статье охарактеризованы особенности интралингвального перевода текстов на ясный и / или простой языки и определены возможности подготовки специалистов в этой сфере. Э.М. Каировой выявлены критерии разграничения понятий «перевод на ясный язык» и «перевод на простой язык», рассмотрены принципы и правила перевода. Н.В. Нечаевой описана специфика применения принципов и правил при переводе текстов на ясный и / или простой языки, выделены компетенции специалистов, необходимые для перевода текстов на ясный и / или простой языки. Исследование речевой практики (примеров перевода текстов на ясный русский язык) позволило Н.В. Нечаевой выявить языковые и внеязыковые факторы, которые необходимо учитывать на этапе предпереводческого анализа исходного текста и коммуникативной ситуации перевода. Обобщение практического опыта подготовки переводчиков на ясный и простой языки в Германии позволило К.-С. Хельмле сделать выводы о возможностях и содержании подготовки специалистов данной сферы в России и мире. Результаты исследования могут быть применены в российских и зарубежных университетах при разработке программ подготовки переводчиков, в государственных и коммерческих организациях при создании доступной среды на ясном и простом языке для эффективной коммуникации с целевой аудиторией. Материалы статьи могут быть полезны практикующим специалистам по межъязыковому переводу для повышения квалификации в сфере интралингвального перевода.

Ключевые слова: интралингвальный перевод, ясный язык, простой язык, цифровая доступность, перевод на ясный язык, перевод на простой язык, подготовка переводчиков.

Цитирование. Нечаева Н. В., Хельмле К.-С., Каирова Э. М. Перевод на ясный и / или простой языки как интралингвальный вид перевода и подготовка переводчиков // Вестник Волгоградского государственного университета. Серия 2, Языкознание. - 2021. - Т. 20, № 3. - C. 99-108. - DOI: https://doi.org/10.15688/jvolsu2.2021.3.9

\section{Перевод на ясный и простой языки как вид интралингвального перевода}

Традиционно перевод рассматривается как акт межъязыковой и межкультурной коммуникации, то есть передача смыслового и прагматического содержания текста, выраженного знаками одного языка, средствами другого языка. Однако существует и другой подход к определению перевода в широком смысле, который базируется на уже ставшей классической концепции Р.О. Якобсона [Якобсон, 1978], согласно которой можно выделить три вида перевода:

- межсемиотический перевод, или трансмутация, - например, сурдоперевод, создание текстов на языке Брайля, передача языковых знаков символами (таблички о запрете курения, дорожные знаки и т. п.);

- межъязыковой перевод, или собственно перевод, - традиционный перевод устных, письменных и аудиовизуальных текстов с одного языка на другой;

- интралингвальный (внутриязыковой) перевод, или переименование, к которому от- носятся такие виды преобразования текста, как реферирование, аннотирование, адаптация текстов с учетом специфики новой целевой аудитории (например, энциклопедических текстов для детей), а также перевод текстов на ясный (далее - ЯЯ) и простой (далее - ПЯ) языки, который выступает объектом исследования в настоящей статье.

Перевод на ЯЯ и / или ПЯ - это интралингвальный устный или письменный перевод (адаптация) текста при сохранении его основного информационного содержания. Такой вид внутриязыкового перевода позволяет сделать текст доступным для максимально широкого круга реципиентов [Нечаева и др., 2020].

Перевод на ЯЯ и перевод на ПЯ - понятия близкие, но не тождественные. Продемонстрировать их различия можно через определение адресатов, целей перевода и характера текстов, которые могут быть переведены на тот или иной язык [Нечаева и др., 2020].

Так, главная целевая аудитория перевода текстов на ЯЯ - люди, у которых по разным причинам недостаточно хорошо сформирован 
навык чтения и развита способность понимать тексты на стандартном русском языке. Чтобы найти нужную информацию, записаться на прием к врачу, прочитать инструкцию, заполнить бланк, им необходима помощь посредника - переводчика, друга, родственника - или текст, который переведен со стандартного русского языка на ясный русский язык. Сферы применения и цели перевода на ЯЯ ограничены кругом бытовых ситуаций и тем, не требующих знаний ни в какой предметной области: а) повышение безопасности жизнедеятельности адресатов за счет различного рода инструкций, памяток, пошаговых руководств; б) повышение качества жизни за счет обеспечения доступа к большему количеству услуг, культурной, общественной жизни и т. п.

Целевая аудитория перевода текстов на ПЯ шире - это так называемый «массовый читатель», то есть люди, которые в силу возраста (как юного, так и пожилого), уровня образования, объема фоновых знаний и т. п. могут испытывать сложности в понимании специальных текстов, написанных стандартным языком. Как показывают результаты различных исследований РІАС, НИУ ВШЭ, исследование доступности Рунета и др., таких людей в России и мире более $80 \%$ - уровень читательской грамотности (функциональное чтение) населения планеты крайне низок. Многим людям требуется помощь и пояснения при чтении стандартных текстов, или же они не читают то, чего не понимают. Таким образом, цели перевода на ПЯ не ограничены, поскольку в эффективной коммуникации заинтересованы все, кто создает тексты, кто хочет быть услышанным своей целевой аудиторией, хочет избежать коммуникативных неудач. ПЯ в качестве средства обеспечения доступности необходим в тех случаях, когда возможностей для перекодирования текста на ЯЯ недостаточно (см.: Исследование обеспечения доступности...; Оценка сложности языка...; Результаты исследования РІААC).

\section{Процесс перевода}

на ясный и простой языки:

\section{базовые принципы и их применение}

Процесс перевода на ЯЯ и ПЯ по своей сути идентичен межъязыковому переводу текстов и включает три базовых этапа: анализ, стратегия и интерпретация-адаптация с учетом новой коммуникативной ситуации, целевой аудитории и т. д. (передача смысла текста на одном языке средствами другого языка - в традиционном межъязыковом переводе). Адаптация без умения глубоко анализировать и понимать целевую аудиторию, коммуникативную ситуацию невозможна.

При переводе для людей с когнитивными нарушениями (аудитория ЯЯ) переводчик должен также понимать психофизиологические особенности восприятия текста/речи этой целевой группой - конкретное мышление, неустойчивое внимание, слабая способность отслеживать логику текста и т. п. (подробно об этом см.: [Брюховских, 2009]).

\section{Принципы и правила перевода на простой и ясный язык}

Базовые принципы и основанные на них правила перевода текстов на ЯЯ и ПЯ сформулированы и подробно проанализированы зарубежными исследователями [Baumert, 2016; 2018; Bredel, Maass, 2017; Usova, 2017; Helmle, 2017] и представителями профильных организаций: Международной ассоциацией «Простой язык» (PLAIN), Международной федерацией «Простой язык» (Plain Federation), Международной ассоциацией поддержки лиц с особенностями интеллектуального развития и их семей «Инклюзивная Европа» (Inclusion Europe).

Важно понимать, что с лингвистической точки зрения правила и принципы перевода на ЯЯ и на ПЯ во многом идентичны, чем, по нашему мнению, и объясняется недостаточно четкое разграничение языков и видов перевода.

Базовые принципы перевода текстов на ПЯ и ЯЯ включают принципы: 1) главенствующей роли читателя; 2) равной позиции; 3) конкретности; 4) личности; 5) частотности; 6) наглядности. На них базируются общие правила адаптации текстов для целей доступности, которые в равной степени применимы для перевода текстов на ПЯ и ЯЯ. Рассмотрим перечисленные принципы подробнее.

1. Принцип главенствующей роли читателя.

Согласно принятым Международной федерацией «Простой язык» постулатам, текст 
только тогда может считаться доступным, когда получатель изложенной в нем информации может легко найти нужную, понять ее и использовать (Plain Federation). Таким образом, текст, создаваемый без учета ситуативного контекста его использования целевой аудиторией, не может считаться доступным, даже если написан простыми словами и короткими предложениями.

2. Принцип равной позиции.

Bce коммуникативные неудачи начинаются с уверенности автора текста в том, что читатель знает и понимает в предмете речи столько же, сколько и сам автор. Успешность коммуникации в данном случае также мало зависит от того, насколько простые, короткие или частотные слова будет выбирать автор главное, понимать, что картина мира и понятийный аппарат адресата позволят ему понять текст в полном объеме и должным образом. Для этого необходимо уметь встать на общую позицию с читателем.

3. Принцип конкретности.

Характерные для официально-делового стиля и юридического дискурса приемы - например, подмена понятий, безличные конструкции, использование пассивного залога и т. п. - делают такие тексты недоступными для людей, которые никогда целенаправленно не учились их читать. Образность и большое количество заложенной в художественные и публицистические тексты эксплицитной информации также препятствуют их полному пониманию целевой аудиторией ЯЯ и ПЯ.

4. Принцип личности.

Отказ от безличных конструкций в пользу прямого указания на читателя, например, в части прав и обязанностей, возникающих у него при подписании договора, информированного согласия на лечение и т. п.

5. Принцип частотности.

При переводе необходимо отдавать предпочтение наиболее частотным словам, избегать узкой терминологии, иностранных слов, аббревиатур, многозначных слов и клише официально-делового стиля. Если термин или аббревиатуру нельзя заменить на распространенную в обывательском обиходе и однозначно понятную языковую единицу, их нужно разъяснить непосредственно в тексте.
6. Принцип наглядности.

Снабжение текста примерами в личной форме позволяет лучше понимать, ассоциировать с собой и запоминать написанное. Кроме того, при переводе текста на ПЯ или ЯЯ рекомендуется иллюстрировать его графическими элементами. Изображения должны быть одинакового стиля, формы, размера и максимально однозначно соотноситься с описываемым предметом или услугой. Это особенно важно при переводе текстов на ЯЯ [Leichte Sprache, 2013].

Правила перевода на ПЯ логично вытекают из этого набора принципов и в каждом отдельном случае выбираются с учетом потребностей аудитории и контекста использования перевода.

Правила перевода на ЯЯ помимо вышеописанных принципов обусловлены также психофизическими особенностями целевой аудитории [Bredel, Maass, 2016; 2017; European standards..., 2014; Helmle, 2017; Usova, 2017$].$ Так, к числу правил, характерных именно для перевода на ЯЯ, относят:

а) сокращение количества слов в предложении;

b) правило «Один вопрос - один текст»;

c) линейность логики и прямая последовательность изложения;

d) «избыточное» (с точки зрения правил «нормального» письма) выстраивание логических связей между частями текста;

е) «избыточное» употребление местоимений;

f) неиспользование больших чисел и операций с ними, знаков другого языка (латиница или римские цифры в русском тексте и т. п.);

g) правило «Ничего для нас без нас»: процесс перевода предполагает участие представителей целевой аудитории ЯЯ, которые выступают в качестве экспертов на этапе редактирования.

\section{Применение базовых принципов и правил интралингвального перевода на ясный язык и «псевдоясный» язык}

Принципы перевода на ЯЯ и ПЯ выступают в качестве базовых ориентиров, результатом выявления закономерностей и обобщения опыта зарубежных практиков перевода 
[Bredel, Maass, 2016; 2017; European standards..., 2014; Helmle, 2017; Usova, 2017]. Далеко не каждый человек, вооружившись таким списком «универсальных» правил, сможет выполнить кажущийся на первый взгляд простым перевод текста на ЯЯ или ПЯ. Для этого необходима специализированная подготовка, базовые переводческие навыки и умения. В противном случае «простое» использование «универсальных» принципов как руководства к действию может привести к созданию текстов на «псевдоясном» языке.

Рассмотрим ряд примеров, представленных на сайте «Цели устойчивого развития Беларуси», точнее странице сайта на ЯЯ (Адаптированная версия сайта...).

\section{Пример № 1}

Исследования - это изучение учеными свойств природы, которые потом применяются в производстве и в сельском хозяйстве.

Например, ученые изучают свойство растения или поведение животного.

Ученые придумывают, как это свойство добавить в механизм или в машину.

\section{Пример № 2}

Кризисы - это войны, стихийные бедствия, экономические потрясения.

Во время экономических потрясений уменьшается выпуск товаров, закрываются фирмы, растет безработица и снижается уровень жизни населения.

Примеры № 1 и 2 отражают попытку перевести текст на ЯЯ с опорой на набор правил. Формально все нормы соблюдены: предложения сравнительно короткие, слова простые, однозначные, однако не каждому, кто читает эти тексты, ясно, что означает фраза ученые добавляют свойство природы в механизм или машину, что такое экономические потрясения или уровень жизни населения, который снижается. Поэтому, видимо, такое объяснение и «адаптация» едва ли будут понятны целевой аудитории версии сайта на ЯЯ - людям с когнитивными нарушениями.

Следующие примеры перевода (№ 3-5) взяты с сайта Института инклюзивного образования Белорусского государственного педагогического университета им. Максима Танка (страница на ЯЯ) (Адаптированная версия сайта...).

\section{Пример № 3 \\ КАКУЮ ПРОФЕССИЮВЫ ПОЛУЧИТЕ В ИНСТИТУТЕ?}

В Институте Вы получите профессию учителя-дефектолога.

Учитель-дефектолог обучает детей с нарушениями речи, слуха, зрения.

Учитель-дефектолог работает с детьми, которые имеют трудности в обучении.

Специалисты адаптировали текст согласно правилам, однако, никто из возможных представителей целевой аудитории не сможет воспользоваться этим текстом: потенциальные иностранные абитуриенты не найдут информации, актуальной для иностранных граждан, а люди с ментальными нарушениями вводятся в заблуждение, якобы они могут сдать вступительные экзамены, поступить в университет и стать дефектологами. Перевод текста формально выполнен, но полностью дисфункционален, не учитывает ситуативного контекста и интересов потенциальных читателей.

\section{Пример № 4 \\ ПО КАКИМ НАПРАВЛЕНИЯМ ВЕДЕТСЯ РАБОТА В ИНСТИТУТЕ?}

В Институте проводятся научные исследования в области инклюзивного и специального образования.

$<_{\text {... }}>$

Институт проводит международные научные конференции, конкурсы, выставки по вопросам инклюзивного и специального образования.

В примере № 4 автор перевода описывает деятельность сотрудников института. Формально этот текст также соответствует основным требованиям к текстам на ЯЯ: предложения достаточно простые, нет аббревиатур, заимствованных и многозначных слов (хотя используется пассивный залог - ведется работа, проводятся исследования - что противоречит правилам перевода на ЯЯ). При этом словосочетания область инклюзивного образования, выставки по вопросам инклюзивного и специального образования слишком абстрактны. Автор использует однозначные слова, но они вряд ли знакомы целевой аудитории. Обращаемся к словарю на сайте, где авторы объясняют значение термина «специальное образование», и видим следующий текст: 
Пример № 5

C

- Специальное образование - это обучение и воспитание детей с особенностями психофизического развития.

Объяснение термина «специальное образование» производится с помощью другого термина из области социальной и коррекционной педагогики - «дети с особенностями психофизического развития». Использование одного правила перевода текста на ЯЯ (пояснение терминов в тексте) происходит параллельно с нарушением важнейшего принципа перевода - принципа частотности (уход от использования терминологии). Ясный ли этот язык? Понятен ли он людям с интеллектуальными нарушениями? В данном случае представляется очевидным, что переводчики интерпретировали принцип частотности субъективно, то есть с позиции автора текста, а не с позиции читателя, хотя для преподавателей и студентов указанного вуза термин «особенности психофизического развития» представляется достаточно частотным и общепринятым.

Чтобы избежать ошибок, обусловленных формальным применением базовых принципов и правил адаптации текстов, необходимо до перевода анализировать коммуникативную ситуацию, в которой использованы исходный и переводной тексты, языковую специфику текста, выявлять те смыслы исходного текста, которые обязательны для передачи в тексте перевода (с учетом их функции и пользы для новой целевой аудитории - получателей переводного текста), определять, какие смысловые части необходимо дополнительно пояснять и как.

Такой подход к переводческому процессу базируется на функциональной теории перевода и, в частности, рекомендациях К. Норд по выполнению анализа переводческого заказа, который должен быть первым этапом переводческого процесса [Nord, 1991]. Прежде всего необходимо узнать, что хочет заказчик, проанализировать лингвистические и нелингвистические особенности исходного текста (включая фоновые знания целевой аудитории и функцию текста) и определить, как и в какой степени их необходимо учитывать при переводе. Только профессиональный подход к переводу может обеспечить качественный результат.
Таким образом, интралингвальный перевод текстов на ЯЯ и ПЯ требует не только знания базовых принципов и правил перевода, но и понимания сути и оснований данных принципов, умения их грамотно применять с учетом особенностей коммуникативной ситуации, что требует особой профессиональной подготовки.

\section{Профессиональная подготовка переводчиков на ясный язык: практический опыт}

Как показывает практика подготовки переводчиков на ЯЯ в Германии, в частности обучающие семинары и курсы повышения квалификации, организованные одним из авторов настоящей статьи - К.-С. Хельмле, многие слушатели только в процессе обучения осознают, что создавать тексты на ЯЯ не так легко, как может показаться сначала. Выполнение практических заданий дается им с большим трудом, а самый распространенный вывод, который они делают после первых занятий: «переводить нужно уметь». Люди думают, что если читаются такие тексты легко, то и переводить / писать на ЯЯ и ПЯ тоже легко, и любой человек может делать это без особого труда. Однако чтобы адекватно переводить тексты на ЯЯ, нужно не только хорошо знать основные правила, но и понимать их суть, уметь грамотно и разумно применять их на практике с учетом специфики конкретного текста и ситуативного контекста в целом. Безусловно, необходим практический опыт перевода. Участники семинаров Кришны-Сары Хельмле уже после первого учебного дня понимают, что большинство текстов из их повседневной жизни сложны для понимания, и способны выявить в этих текстах основные причины недоступности (например, термины, слишком длинные предложения). Они также могут упростить небольшие части текста, но, как правило, до уровня ПЯ, а не ЯЯ. Бывают исключения, но они лишь подтверждают правило.

\section{Возможности профессиональной подготовки}

Существуют разные возможности профессиональной подготовки переводчиков на ПЯ и ЯЯ. 
В качестве примера можно привести магистерскую программу «Безбарьерная коммуникация» университета г. Хильдесхайм (Германия). Четыре семестра посвящены теории и практике коммуникационной доступности. ЯЯ и интралингвальный перевод - один из базовых модулей этой образовательной программы (M.A. Barrierefreie Kommunikation).

Обучение в университете г. Хильдесхайм - возможность получить фундаментальную подготовку по переводу текстов на ЯЯ. Однако специалистов в этой области можно эффективно готовить и в рамках курсов повышения квалификации для лиц, получивших общее переводческое образование - они обладают базовыми переводческими компетенциями и могут сравнительно быстро научиться применять их в практике интралингвального перевода. К такому выводу мы пришли на основе многолетнего опыта разработки и ведения курсов повышения квалификации для переводчиков и преподавателей перевода в рамках Международной летней школы в Гермресхайме (Online-Akademie für Übersetzen \& Dolmetschen).

В структуру курсов подготовки переводчиков на ЯЯ и ПЯ включены небольшой блок теоретических занятий по лингвистике текста, теории коммуникации и перевода и практические занятия (основная часть курса). Рекомендуется также включать в программу специальные блоки по отраслям: например, модуль «Правовая коммуникация и право» в подготовку переводчиков на ЯЯ (ПЯ) в сфере права.

Еще одно направление обучения квалифицированных специалистов по ЯЯ и ПЯ подготовка преподавателей перевода текстов на ЯЯ и ПЯ. Такими преподавателями могут стать специалисты, которые уже имеют опыт преподавания (например, преподаватели перевода), прошли обучение по основам перевода и имеют опыт перевода текстов на ЯЯ. Такие преподаватели могут самостоятельно разрабатывать и применять методические инструменты и материалы для подготовки переводчиков на ЯЯ. Стать преподавателями перевода текстов на ЯЯ могут не только преподаватели перевода, однако, для их подготовки потребуется разработка специальной комплексной программы, включающей все пере- численные выше блоки, а также дополнительно основы дидактики и методики преподавания перевода.

\section{Заключение}

Аналитическое осмысление научной литературы, изучение опыта зарубежных теоретиков и практиков перевода позволяют сделать ряд выводов.

Во-первых, перевод текстов на ЯЯ и ПЯ - это интралингвальный вид перевода, который позволяет делать тексты доступными для максимально широкого круга реципиентов (ПЯ) или для реципиентов с особыми потребностями (ЯЯ).

Во-вторых, перевод текстов на ЯЯ и ПЯ - сложный когнитивный процесс, который требует комплексной профессиональной подготовки. Внутриязыковое «переписывание» текстов по формальным правилам без понимания сути переводческого процесса может привести к созданию текстов на «псевдоясном языке».

В-третьих, подготовка переводчиков на ЯЯ и ПЯ - комплексный процесс, который реализуется, как минимум, в двух аспектах: теоретическом (основы теории коммуникации, теории перевода, базовые принципы перевода текстов на ЯЯ) и практическом (занятия по практике перевода, включая предпереводческий анализ языковых и неязыковых особенностей текста).

Существует успешный опыт подготовки переводчиков на ЯЯ как в рамках краткосрочных курсов повышения квалификации для переводчиков на иностранные языки и преподавателей перевода, так и в рамках основных образовательных программ университетов (Германия).

В России в настоящий момент подготовка таких специалистов не ведется, однако развитие этого направления представляется весьма перспективным. Разработка учебных, методических и практических материалов по ясному и простому русскому языку осуществляется в рамках проекта Ассоциации преподавателей перевода «Перевод на ясный и простой языки в России», ведущими экспертами которой выступают авторы настоящей статьи. В рамках проекта в настоящий момент 
разрабатывается информационный ресурс на ЯЯ (https://ясно.сайт), готовится к апробации курс повышения квалификации для переводчиков, а также планируется разработка курса по подготовке преподавателей перевода в данной сфере.

\section{СПИСОК ЛИТЕРАТУРЫ}

Брюховских Л. А., 2009. Особенности понимания речи у детей с умственной отсталостью // Вестник КГПУ им. В.П. Астафьева. № 1. С. 82-87.

Нечаева Н. В., Хельмле К.-С., Каирова Э. М., 2020. Перевод на ясный и простой языки: зарубежный опыт и перспективы в России // Вестник ПНИПУ. Проблемы языкознания и педагогики. № 3. С. 8-24. DOI: https://doi.org/10.15593/ 2224-9389/2020.3.1.

Якобсон Р. О., 1978. О лингвистических аспектах перевода // Вопросы теории перевода в зарубежной лингвистике. М. : Международные отношения. С. 16-24.

Baumert A., 2016. Leichte Sprache-Einfache Sprache. Literaturrecherche, Interpretation, Entwicklung. Hannover : Bibliothek der Hochschule Hannover. URL: http://nbn-resolving.de/urn:nbn:de:bsz:960opus4-6976 (date of access:17.02.2021).

Baumert A., 2018. Einfache Sprache. Verständliche Texte schreiben. Unter Mitwirkung von Annette Verhein-Jarren. Münster : Spaß am Lesen.

Bredel U., Maass Ch., 2016. Leichte Sprache. Theoretische Grundlagen. Orientierung für die Praxis. Berlin : Dudenverlag. (Sprache im Blick), Kapitel 6.

Bredel U., Maass Ch., 2017. Ratgeber Leichte Sprache Die wichtigsten Regeln und Empfehlungen für die Praxis. Duden.

European standards for making information easy to read and understand, 2014. URL: http://easy-to-read.eu/ wp-content/uploads/2014/12/EN_Information_ for all.pdf. (date of access: 17.02.2021).

Helmle K.-S., 2017. Leichte Sprache. Ein Überblick für Übersetzer. Berlin : BDÜ-Fachverlag. $150 \mathrm{p}$.

Leichte Sprache-Die Bilder, 2013. Bremen : Verlag der Budesvereinigung Lebenshilfe e.V. $178 \mathrm{~S}$.

Nord Ch., 1991. Text Analysis in Translation. Theory, Method, and Didactic Application of a Model for Translation-Oriented Text Analysis. Translated from the German by Christiane Nord and Penelope Sparrow. Amsterdam : Atlanta GA, Rodopi. $250 \mathrm{p}$.

Usova O., 2017. Leichte Sprache in Russland // "Leichte Sprache" im Spiegel theoretischer und angewandter Forschung. Leipzig : Frank \& Timme GmbH. P. 457-461.

\section{ИСТОЧНИКИ}

Адаптированная версия сайта на ясном языке «Цели устойчивого развития Беларуси». URL: http://sdgs.by/clear_lang/.(дата обращения: 17.02.2021).

Адаптированная версия сайта на ясном языке Института инклюзивного образования Беларусского государственного педагогического университета им. Максима Танка. URL: https:// iio.bspu.by. (дата обращения: 17.02.2021).

Исследование обеспечения доступности интернетресурсов Рунета для людей с ограниченными возможностями здоровья (OB3). URL: https://perspektiva-inva.ru/userfiles/download/ Accessibility_of_Runet_2013.pdf(дата обращения: 29.11.2020).

Оценка сложности языка законов: исследование НИУ ВШЭ. URL: https://icef.hse.ru/data/2020/ 03/18/1567931010/Оценка\%20сложности \%20zзаконов.pdf(дата обращения: 29.11.2020).

Результаты исследования PIAAC. URL: https:// www.oecd.org/skills/piaac/publications/ PIAAC_Technical_Report_2019.pdf(дата обращения: 29.11 .2020$)$.

Inclusion Europe. URL: https://www.inclusioneurope.eu (date of access: 17.02.2021).

M.A. Barrierefreie Kommunikation, Universität Hildesheim. URL: https://www.uni-hildesheim.de/ leichtesprache/ma-barrierefreie-kommunikation (date of access: 17.02.2021).

Online-Akademie für Übersetzen \& Dolmetschen. URL: https://www.iris-akademie.de (date of access: 17.02.2021).

\section{REFERENCES}

Bryukhovskikh L.A., 2009. Osobennosti ponimaniya rechi u detey s umstvennoy otstalostyu [Peculiarities of Speech Understanding in Children with Intellectual Disabilities]. Vestnik KGPU im. V.P. Astaf'eva [Bulletin of Krasnoyarsk State Pedagogical University], no. 1, pp. 82-87.

Nechaeva N.V., Hel'mleK.-S., Kairova Je.M., 2020. Perevod na jasnyj i prostoj jazyki: zarubezhnyj opyt i perspektivyv Rossii [Translating into Easy and Plain Languages: International Practice and Prospects for Russia]. Vestnik PNIPU. Problemy jazykoznanija $i$ pedagogiki [PNRPU Linguistics and Pedagogy Bulletin], no. 3, pp. 8-24. DOI: https://doi.org/ 10.15593/2224-9389/2020.3.1.

Jakobson R.O., 1978. O lingvisticheskih aspektah perevoda [On the Linguistic Aspects of Translation]. Voprosy teorii perevoda $v$ zarubezhnoj lingvistike [Issues of Translation 
Theory in Foreign Linguistics]. Moscow, Mezhdunarodnye otnosheniya Publ., pp. 16-24.

Baumert A., 2016. Leichte Sprache - Einfache Sprache. Literaturrecherche, Interpretation. Hannover, Bibliothek der Hochschule Hannover. URL: http:// nbn-resolving.de/urn:nbn:de:bsz:960-opus4-6976 (accessed 17 February2021).

Baumert A., 2018. Einfache Sprache. Verständliche Texte schreiben. Unter Mitwirkung von Annette Verhein-Jarren. Münster, Spaß am Lesen.

Bredel U., Maass Ch., 2016. Leichte Sprache. Theoretische Grundlagen. Orientierung für die Praxis. Berlin, Dudenverlag. (Sprache im Blick), Kapitel 6.

Bredel U., Maass Ch., 2017. Ratgeber Leichte Sprache Die wichtigsten Regeln und Empfehlungen für die Praxis. Duden.

European Standards for Making Information Easy to Read and Understand, 2014. URL: http:// easy-to-read.eu/wp-content/uploads/2014/12/ EN_Information_for_all.pdf (accessed 17 February 2021).

Helmle K.-S., 2017. Leichte Sprache. Ein Überblick für Übersetzer. Berlin, BDÜ-Fachverlag. 150 p.

Leichte Sprache - Die Bilder, 2013. Bremen, Verlag der Budesvereinigung Lebenshilfe e.V. 178 p.

Nord Ch., 1991. Text Analysis in Translation. Theory, Method, and Didactic Application of a Model for Translation-Oriented Text Analysis. Translated from the German by Christiane Nord and Penelope Sparrow. Amsterdam, Atlanta GA, Rodopi. 250 p.

Usova O., 2017. Leichte Sprache in Russland. "Leichte Sprache" im Spiegel theoretischer und angewandter Forschung. Leipzig, Frank \& Timme GmbH, pp. 457-461.

\section{SOURCES}

Adaptirovannaja versija sajta na jasnom jazyke «Celi ustojchivogo razvitija Belarusi» [Adapted
Version of the "Sustainable Development Goals in Belarus" Website in Clear Language]. URL: http://sdgs.by/clear_lang (accessed 17 February 2021).

Adaptirovannaja versija sajta na jasnom jazyke Instituta inkljuzivnogo obrazovanija Belarusskogo gosudarstvennogo pedagogicheskogo universiteta im. Maksima Tanka [Adapted Version of the Institute of Inclusive Education of the BSPU Website in Clear Language]. URL: https://iio.bspu.by (accessed 17 February2021).

Issledovanie obespechenija dostupnosti internetresursov Runeta dlja ljudej s ogranichennymi vozmozhnostjami zdorov'ja (OVZ) [Study on Accessibility of Runet Internet Resources for People with Disabilities]. URL: https:// perspektiva-inva.ru/userfiles/download/ Accessibility_of_Runet_2013.pdf (accessed 29 November 2020 ).

Ocenka slozhnosti jazyka zakonov: issledovanie NIU VShJe [Assessing the Complexity of the Language of Laws: A Study by the National Research University Higher School of Economics]. URL: https://icef.hse.ru/data/ 2020/03/18/1567931010/Ocenka\%20slozhnosti \%20zzakonov.pdf (accessed 29 November 2020).

Rezul'taty issledovanija PIAAC [Results of the PIAAC Study]. URL: https://www.oecd.org/ skills/piaac/publications/PIA A C Technical_Report_2019.pdf (accessed 29 November 2020).

Inclusion Europe. URL: https://www.inclusioneurope.eu (accessed 17 February 2021).

M.A. Barrierefreie Kommunikation, Universität Hildesheim. URL: https://www.uni-hildesheim.de/ leich tesprache/ma-barrierefreiekommunikation (accessed 17 February 2021).

Online-Akademie für Übersetzen \& Dolmetschen. URL: https://www.iris-akademie.de (accessed 17 February 2021). 


\section{Information About the Authors}

Natalya V. Nechaeva, Candidate of Sciences (Philology), Associate Professor, Herzen State Pedagogical University of Russia, Reki Moyki Emb., 48, 1 korpus, 191186 Saint Petersburg, Russia, nnechaeva@herzen.spb.ru,https://orcid.org/0000-0001-8731-9118

Krishna-Sara Helmle, Founder and Business Owner, Translation Company and Consultancy for Easy-to-Read and Plain Language "Textöffner ${ }^{\circledR}$ ", Mirabeauweg, 2, 72072 Tübingen, Germany, info@leicht-verstehen.de, https://orcid.org/0000-0003-3154-7722

Emma M. Kairova, Founder and CEO at LSP and Mentorship project for translators "PROtranslation", Kirova St, 2G/77, 360030 Nalchik, Russia, ekairova@protranslation.ru, https://orcid.org/0000-0002-0892-0608

\section{Информация об авторах}

Наталья Викторовна Нечаева, кандидат филологических наук, доцент кафедры перевода, Российский государственный педагогический университет им. А.И. Герцена, набережная реки Мойки, 48, 1-й корпус, 191186 г. Санкт-Петербург, Россия, nnechaeva@herzen.spb.ru, https://orcid.org/0000-0001-8731-9118

Кришна-Сара Хельмле, основатель и директор, Переводческая и консалтинговая компания Textöffner®, Мирабеаувег, 2, 72072 г. Тюбинген, Германия, info@leicht-verstehen.de, https://orcid.org/0000-0003-3154-7722

Эмма Магомедовна Каирова, директор, Переводческая компания и наставнический проект для переводчиков ООО «Протранслейшн», ул. Кирова, 2Г/77, 360030 г. Нальчик, Россия, ekairova@protranslation.ru, https://orcid.org/0000-0002-0892-0608 